\title{
Job Stress Level and Its Effects among Nurses Working In Critical Care Areas during Hajj Season in King Abdullah Medical City, A Cross Sectional Study
}

Samina Akhtar, Mrs. Farzana Kousar, Mrs. Nada Tariq, Dr. Tharwat Aisa ${ }^{*}$

Department of Critical Care Medicine, King Abdullah Medical City, Makkah Saudi Arabia

DOI: $10.36348 /$ SJNHC.2019.v02i09.008 $\quad$ | Received: 30.08.2019| Accepted: 24.09.2019| Published: 30.09 .2019

*Corresponding author: Tharwat Aisa

Abstract

Background and rationale: Job stress has become a major problem in recent period particularly in nursing profession. Work stress is the second prevailing problem related to health. The background of critical care areas is extremely hectic and stressful, that result from frequent emergencies, extraordinary high-tech complexity, and absorption of severely wounded patients subject to abrupt alterations in their health condition. Stress in the hajj season seems to be at its peak because nurses have consecutive 15 shifts and handling a high numbers of multicultural and multilingual patients. Objective of the study: To find out the level of job related stress and its related consequences among nurses working in the critical care areas of King Abdullah Medical City during hajj season. Methods: We used a questionnaire of 35 questions with likert scale as $1=$ Never, $2=$ occasionally, $3=$ frequently, $4=$ most often and $5=$ always. In addition, we targeted all the nurses working in critical care area during hajj time of 2017. Results: From 100 (n=100) participants 39\% responded as having mild stress, $47 \%$ participants having moderate stress and $14 \%$ nurses facing severe degree of stress. the majority $51 \%$ of this sample nurses showed moderate to severe degree of job satisfaction and a small percentage $2 \%$ were mildly satisfied with their job. Moreover, almost half participants $49 \%$ have mild mental and physical health problems due to stress while $22 \%$ to $29 \%$ respondents facing moderate to severe degree of health problems. Furthermore, $40 \%$ of the staff experienced a mild degree of being emotionally drained at work, while $33 \%$ of them had severe degree and $27 \%$ experienced a moderate degree. Additionally, 55\% of the nurses responded that they are not participating in job related decisions. More than half of nurses were apathetic towards their colleagues and a maximum number of participant have feeling of incompetence. The results of an open-ended question for techniques to cope with the stress level, however, respondents can choose more than one option. Having tea, coffee or any other beverages were at the maximum numbers followed by deep breathing. Exercise, yoga or meditation was at minimum number as only $20 \%$ and $27 \%$ musical therapy. Gender and overall physical and mental health found to be the independent risk factors for stress in the multi-regression analysis. Conclusion: Overall job stress level is moderate among nurses in all critical care areas in our hospital. It is associated with a variety of personal and institutional factors and it needs further studies to detect its effects on patients care and outcome.

Keywords: Job stress, Nurses, Intensive care, Hajj time.

Copyright @ 2019: This is an open-access article distributed under the terms of the Creative Commons Attribution license which permits unrestricted use, distribution, and reproduction in any medium for non-commercial use (NonCommercial, or CC-BY-NC) provided the original author and source are credited.

\section{INTRODUCTION}

There are many studies on stress among nurses related to their job. Work stress is the second prevailing problem related to health. In 27 European countries, $22 \%$ of nurses suffered from stress. Moreover, in 15 European countries annual budget for stress related work increased to 20 billion Euros, making it a solid business case. In addition, this data directs that further work need to be conducted in all these aspects to lessen or handle the magnitude of job stress for individual, society and organization. More theoretical study is desired on stress and problems related to it. Job stress has become a major problem in recent period particularly in nursing profession [1].

Recently, Job stress mainly in the nursing career has become a significant problem. Nurses working in the hospital settings tend to be exposed to the greatest level of job stressors; study had shown in comparison to other health care professionals that nurses are facing utmost stress, highest physical and psychological tension [2]. Researcher also concludes its negative effects on nurses' job satisfaction [3] and increasing number of turn over and absenteeism [4]. 
This profession particularly in the hospital setting holds numerous factors that can cause stress, it needs extremely demanding skill for instance, and teamwork in diverse situation, accountability for assigned patient and responsibility of shift work [5].

Critical care unit's objective is to promote appropriate and fast recovery to the patients admitted to a hospital who are seeking intensive care due to serious injury and illness that put their life at risk, and this environment is surrounding by poor physical and psychological conditions, where every profession is enough skillful to apply and practice prevailing procedures, methods and techniques. To achieve that, nurses are required to be ready all the time to accomplish multifarious tasks that include busy schedule, demanding skillful practice, physical and psychological preparation.

The presence of nurses in these units is vital. Nurses perform managerial and clinical activities based on assistance, and play a crucial part to build the patient physical and psychological integrity.

The background of critical care areas is extremely hectic and stressful, that result from frequent emergencies, extraordinary high-tech complexity, and absorption of severely wounded patients subject to abrupt alterations in their health condition. So, due to this emotionally uncertain picture, environment of critical care areas is considered as tense for professionals, patients and their families.

Mostly research found that nurses who work with critically ill patients are more likely to have stress, while other studies highlight that the job burden and interpersonal relationship issues are the obvious variables causing stress. It is extremely significant to recognize the reality of stress among the staffs who are working in critical care areas.

The understanding required among other things, the identification of aspect that hinder their performance and that can lead to the lack of care of the patient and family, creating space, stress and team anguish. These nurses go through an emotional sketch of variation during their work hours, and that can relate to the exhaustion and stress from activities of care giving, where advanced and sophisticated services and prompt response to emergency are required.

In $\mathrm{KAMC}$, we can see that a high number of nurses resigned in last two years, increasing the numbers of sick leaves and staff mostly complain for weariness and so on. These all aspects are Predisposing for occupational stress. Stress in the hajj season seems to be at its peak because nurses have consecutive 15 shifts and handling a high numbers of multicultural and multilingual patients. Critical care areas will include ICU, CCU, CSICU \& NICU. Health facilities in Mecca celebrates Hajj season every year in the month of Dhalhajj from $1^{\text {st }}$ to $15^{\text {th }}$ of this sacred month.

\section{Objective of the study}

The purpose of this study was to find out the level of job related stress among nurses working in critical care areas of King Abdullah Medical City during hajj season and to find out effects of stress on nurse's job satisfaction, physical and mental health.

\section{Objectives are}

- To find the level of job related stress

- To find its effects on nurse's job satisfaction

- To find out its effects on nurse's mental and physical health

- To recommend interventions for release of job stress in future hajj seasons.

\section{Study design}

- Descriptive

- Cross sectional

- Its quantitative data will be collected through a questionnaire

- Convenience sampling

\section{Study population}

This study was take place in all critical care areas of KAMC during Hajj season 2017 and questionnaire will be anonymous.

\section{Inclusive Criteria}

Nurses who are willing to fill questionnaire and working on bed side was included in this.

\section{Exclusion criteria}

- Nurses who was be absent during data collection phase.

- Nurses who was not ready to participate in our study

\section{Study Procedure}

After receiving official permission from KAMC IRB, the purpose of this research and the procedures was explained to the nurses to get their support. A sheet with all required information on it was being distributed to the nurses and a verbal consent was being obtained because of anonymous questionnaire. The researcher was keep confidentiality of nurses at all extent. Nurses have right to participate in the research or not, and they can withdraw from the research at any time without any disadvantage. Simple random method was being used to get this study sample population.

\section{Data Collection and Management}

The investigator was distributing questionnaire to get experience of staff nurses on job stress level and its effects among them working in critical care area. This questionnaire consists of 35 questions with likert scale as $1=$ Never, 2 = occasionally, 3 = frequently, $4=$ most often and $5=$ always. 


\section{Sample Size}

We are targeting all nurses working in critical care area.

\section{Duration of the Study}

Two months

\section{Statistical Analysis Plan}

Data was imported from the excel sheet into SPSS version 23 and saved in a SPSS system file to which variable labels and value labels were added. Invariable distributions were examined for anomalies, and errors were corrected. Summary statistics was obtained as appropriate. Continuous variables were compared between the study subgroups using Student's $\mathrm{T}$ test or regression test $\mathrm{A}$ multivariable logistic regression model might be used to explore the predictors of variable outcome measures. A significance level of $<0.05$ was used for all tests.

\section{Publication}

The results of this research will be published to either national or international publications. The main credit in publication will go to the principal investigator and co-investigators.

\section{Ethical Part \& Confidentiality}

Ethical approval was sought from KAMC IRB before the study and verbal consent was obtained from the participants. After getting official permission from KAMC IRB, the purpose of this research and the procedures was explained to the nurses to obtain their cooperation. An information sheet explains the study details were distributed to the nurses. Verbal consent was obtained. Signed consent was not taken because nurses were not identified on questions, only code will be used. Nurses are allowed to choose whether to participate or not, and they have the right to withdraw from the study at any time without penalty.

\section{DATA ANALYSIS AND DISCUSSION INTRODUCTION}

The data collection during this study was done through collecting questionnaires of close ended except last open ended question from individual participant. First table explains demographic information of participants and next tables displays results of study analysis.

\section{Demographic Information of the Participants}

This section included age, gender, country of birth, total years of professional nursing experience and years' experience in KAMC during Hajj Season. Data derived from these questions were analyzed quantitatively and presented in tables.

Table-1: Demographic Information of the Participants

\begin{tabular}{|c|c|c|}
\hline Variable & Frequency & Valid Percent \\
\hline \multicolumn{3}{|l|}{ Gender } \\
\hline Male & 48 & 48.0 \\
\hline Female & 52 & 52.0 \\
\hline \multicolumn{3}{|l|}{ AGE } \\
\hline $20-25$ & 4 & 4.0 \\
\hline $26-30$ & 44 & 44.0 \\
\hline $31-35$ & 43 & 43.0 \\
\hline Above 35 & 9 & 9.0 \\
\hline \multicolumn{3}{|l|}{ Country of birth } \\
\hline Saudi Arabia & 6 & 6.0 \\
\hline Philippine & 21 & 21.0 \\
\hline India & 39 & 39.0 \\
\hline Pakistan & 20 & 20.0 \\
\hline Jordan & 7 & 7.0 \\
\hline Other & 7 & 7.0 \\
\hline \multicolumn{3}{|c|}{ Current area of working } \\
\hline ICU & 43 & 43.0 \\
\hline $\mathrm{CCU}$ & 22 & 22.0 \\
\hline CSICU & 14 & 14.0 \\
\hline NICU & 21 & 21.0 \\
\hline \multicolumn{3}{|c|}{ Total years of professional experience } \\
\hline $1-4$ & 9 & 9.0 \\
\hline $4-8$ & 48 & 48.0 \\
\hline $8-12$ & 35 & 35.0 \\
\hline More than 12 & 8 & 8.0 \\
\hline \multicolumn{3}{|c|}{ Experience in KAMC during Hajj season } \\
\hline 1 Year & 6 & 6.0 \\
\hline 2 Years & 20 & 20.0 \\
\hline 3 Years & 21 & 21.0 \\
\hline More than 3 years & 53 & 53.0 \\
\hline
\end{tabular}

From the $100(\mathrm{n}=100)$ only 48 participants were males and 52 were females. 
Highest numbers of respondents were between 26-30 years old followed by 31-35 years old. While there were only 4 respondents fell between 20-25 years of age and 9 members were above 35 years old. Most participants originated from the India $39 \%$, followed by the Philippine nurses $21 \%$, Pakistani nurses $20 \%$, and Jordanian nurses $7 \%$, Saudi Nurses $6 \%$ and various mix nationalities at $7 \%$.

Maximum nurses were from ICU making 43\% of all numbers and minimum numbers of nurses were From CSICU (Post cardiac surgery intensive care unit) as only $14 \%$, from CCU (cardiac care unit) and NICU (neuro intensive care unit) there were 22 and 21 nurses respectively. Their years of professional experience in nursing varied from 1 year to more than 12 years with majority of the participants belonging to 4 to 8 year's range of experience group followed by 35 nurses having 8 to 12 years of experience. There was almost equal participant of 1-4 and more than 12 years of experience. Their total nursing experience in KAMC during hajj season varied from 1 to 3 years with most of them $53 \%$ has more than 3 years of experience in taking care of hajj patients.

Table-2: Level of stress among nurses

\begin{tabular}{|lccr|}
\hline Stress among nurses & Mild & Moderate & Severe \\
N (\%) & N (\%) & N (\%) & N (\%) \\
\hline Overall level of stress & $39 \%$ & $47 \%$ & $14 \%$ \\
Individual components of stress & & & \\
You feel excessive workload & $43 \%$ & $32 \%$ & $25 \%$ \\
You have to rush to complete task & $44 \%$ & $25 \%$ & $31 \%$ \\
Finishing late your assigned work & $77 \%$ & $12 \%$ & $11 \%$ \\
Achieving more than time allows & $48 \%$ & $23 \%)$ & $29 \%$ \\
Hospital expects more than reasonably & $43 \%$ & $29 \%$ & $28 \%$ \\
possible & & & \\
\hline
\end{tabular}

From $100 \quad(\mathrm{n}=100)$ participants $\quad(39 \%)$ responded as having mild stress, $47 \%$ participants having moderate stress and $14 \%$ nurses facing severe degree of stress. Maximum numbers (77\%) showed they are never or occasionally finishing late their assigned task. Responses for being workloaded were mild to moderate.

Table-3: Stress factors of nurse's job satisfaction

\begin{tabular}{|c|c|c|c|}
\hline $\begin{array}{c}\text { Nurses job satisfaction } \\
\mathbf{N}(\%)\end{array}$ & Mild N (\%) & Moderate N (\%) & Severe N (\%) \\
\hline Overall satisfaction & $2(2.0)$ & $47(47.0)$ & $51(51.0)$ \\
\hline $\begin{array}{c}\text { Individual components of job } \\
\text { satisfaction }\end{array}$ & & & $55(55.0)$ \\
\hline Undervalued at your work & $23(23.0)$ & $22(22.0)$ & $68(68.0)$ \\
\hline Afraid to express your needs & $12(68.0)$ & $20(20.0)$ & $15(15.0)$ \\
\hline Participating in job related decisions & $55(55.0)$ & $30(30.0)$ & $51(41.0)$ \\
\hline Really enjoying the type of your work & $40(40.0)$ & $19(19.0)$ & $59(59.0)$ \\
\hline Want to change area of practice & $25(25.0)$ & $16(16.0)$ & $55(55.0)$ \\
\hline Apathetic toward your colleagues & $25(25.0)$ & $20(20.0)$ & $77(77.0)$ \\
\hline Having strong sense of commitment & $9(9.0)$ & $14(14.0)$ & $51(51.0)$ \\
\hline toward your work & $22(22.0)$ & $27(27.0)$ & $88(88.0)$ \\
\hline Constantly looking for challenges & $4(4.0)$ & $28(8.0)$ & $49(49.0)$ \\
\hline Feeling of incompetence & $39(39.0)$ & $20(20.0)$ & $41(41.0)$ \\
\hline Apathetic toward your client & & & \\
\hline Being valued from your client & & & \\
\hline
\end{tabular}

Table 3 displays that the majority (51\%) of this sample nurses showed severe to moderate degree of job satisfaction and a small percentage (2\%) were mild satisfied from their job.

In individual components a very large number $(88 \%)$ respondents are severely feel incompetent, $68 \%$ are afraid to express their needs and more than half number of nurses think they are undervalued at their work place, want to change area of work and apathetic toward their colleagues. $77 \%$ of nurses have strong sense of commitment toward their work and $(51 \%)$ are constantly looking for challenges. Above than 50\% 
numbers showed mild participation in decisions related

to their job.

Table-4: Stress factors of nurse's mental and physical health

\begin{tabular}{|lccc|}
\hline $\begin{array}{l}\text { Stress factors on mental and } \\
\text { Physical health }\end{array}$ & Mild & Moderate & Severe \\
$\mathbf{N}(\%)$ & $\mathbf{N}(\%)$ & $\mathbf{N}(\%)$ & N (\%) \\
& & & \\
\hline $\begin{array}{l}\text { Overall physical and mental condition } \\
\text { Individual components of Stress factors on mental and physical health }\end{array}$ & $49(49.0)$ & $29(29.0)$ & $22(22.0)$ \\
Emotionally drained at work & $40(40.0)$ & $27(26.0)$ & $33(33.0)$ \\
Feel low morale & $56(56.0)$ & $30(30.0)$ & $14(14.0)$ \\
Working environment increases anxiety $57(57.0)$ & $9(9.0)$ & $34(34.0)$ \\
Fatigued from work & $34(34.0)$ & $28(28.0)$ & $38(38.0)$ \\
Physical problems like headache and & $57(57.0)$ & $12(12.0)$ & $31(31.0)$ \\
\hline
\end{tabular}

This table shows that in overall almost half participants $(49 \%)$ have mild mental and health problems due to stress and $29 \%$ ) to (22\%) respondents facing moderate to severe degree of health problems respectively.
Individual components $(40 \%)$ have mild, $(33 \%)$ severe and (27\%) moderate degree of emotionally drained at work. Likewise majority of responses for all individual components were mild degree except fatigued from work that was (38\%) in severe degree.

Table-5: Interventions for release of job stress

\begin{tabular}{|l|c|}
\hline Techniques & Frequencies \\
\hline Deep breathing & 41 \\
Drinking tea, coffee or any other beverage & 63 \\
Exercise, yoga or meditation & 20 \\
Musical therapy & 27 \\
\hline
\end{tabular}

Table 5 displays results of open ended question for techniques to cope with stress level, respondents can choose more than one options. Having tea, coffee or any other beverages were at the maximum numbers followed by deep breathing. Exercise, yoga or meditation was at minimum number as only $(20 \%)$ and (27\%) musical therapy.

Table-6: Reliability analysis

\begin{tabular}{|l|l|l|}
\hline Scale & Number of items & Cronbach's Alpha \\
\hline Level of stress & 5 & .755 \\
\hline Job satisfaction & 11 & .518 \\
\hline Effects on physical and mental health & 7 & .823 \\
\hline
\end{tabular}

Reliability analysis shows that scale to measure level of stress and stress effects on nurses physical and mental health is reliable and scale for job satisfaction has value less than 7 . 
Table-7: Correlation analysis

\begin{tabular}{|l|l|l|l|}
\hline & Overall stress & Overall satisfaction & $\begin{array}{l}\text { Overall physical } \\
\text { and mental } \\
\text { health status }\end{array}$ \\
\hline Overall stress & 1 & -.284 & .632 \\
$\begin{array}{l}\text { Overall } \\
\text { satisfaction }\end{array}$ & -.284 & 1 & -.477 \\
$\begin{array}{l}\text { Overall physical } \\
\text { and mental } \\
\text { health status }\end{array}$ & 0.632 & -.477 & 1 \\
\hline
\end{tabular}

Table 7 shows association of stress with satisfaction is negative while it's positive with physical and mental health status. There is also negative association between satisfaction, physical and mental health status.

Table-8: T. Test

\begin{tabular}{|l|l|l|l|}
\hline variables & In ICU & NON ICU & P VLUE \\
\hline overall physical and mental health status & 2.6615 & 2.8053 & .155 \\
\hline overall satisfaction & 3.5136 & 3.5111 & .981 \\
\hline overall stress level & 2.8992 & 2.5906 & .049 \\
\hline
\end{tabular}

Table-9: Regression

\begin{tabular}{|c|c|c|c|c|c|}
\hline \multicolumn{5}{|c|}{ Coefficients } & \\
\hline \multirow[t]{2}{*}{ Model } & \multicolumn{2}{|c|}{ Unstandardized Coefficients } & \multirow{2}{*}{$\begin{array}{l}\text { Standardized Coefficients } \\
\text { Beta }\end{array}$} & \multirow[t]{2}{*}{$\mathbf{t}$} & \multirow[t]{2}{*}{ Sig. } \\
\hline & $\mathrm{B}$ & Std. Error & & & \\
\hline (Constant) & 2.047 & .237 & & 8.633 & .000 \\
\hline Gender & -.070 & .082 & -.077 & -.853 & .396 \\
\hline Overall Physical Mental health & .222 & .066 & .393 & 3.379 & .001 \\
\hline Overal_stress & .077 & .069 & .130 & 1.122 & .265 \\
\hline Experience Binary & .037 & .106 & .040 & .346 & .730 \\
\hline Hajj Experience & .143 & .089 & .159 & 1.612 & .110 \\
\hline Age Binary & -.189 & .107 & -.209 & -1.767 & .081 \\
\hline
\end{tabular}

\section{DISCUSSION AND CONCLUSION}

Analysis of this study shows that there is significant high level of stress among nurses in ICU than nurses working in other critical care areas. The occupational stress amongst health care professionals in general and especially is currently a major concern in health policy. Literature indicates that stress denotes various psycho-social situations which tend to produce disorganization of behavior, including physical and mental illnesses.

Overall job stress level was moderate in all critical care areas. Half of the nurses responded that they are satisfied with their job and only 2 nurses replied that they have mild degree of job satisfaction. It is important to note that other studies have also indicated positive job satisfaction [6]. In individual components of job satisfaction nurses are being undervalued at their work area, they are afraid to express their needs, 55\% nurses responded that they are not participating in job related decisions. Occupational stress among nurses is associated with a variety of personal and institutional factors. Interesting fact was that $40 \%$ to $41 \%$ nurses were really enjoying their type of work as mild and severe respectively and only $19 \%$ nurse's response lies in the middle. More than half of the nurses were apathetic toward their colleagues and a maximum number of participant have feeling of incompetence. The type of physical and mental health problem due to occupational stress revealed by this study was getting fatigued, experiencing headache and sleeplessness.

The study found that, majority of the nurses adopt the following occupational stress management strategies which includes; prayers, reading books, resting, sleeping, chatting with friends and families, by just ignoring the stressful event, smoking and spiritual therapies. The findings from occupational stress management strategies revealed that in order to manage 
stress, most of the nurses prefers Drinking tea, coffee or any other beverage.

This study suggests that even though a large number of nurses described experiencing stress, somewhat paradoxically, they seem to be content with their work. The findings that nurses are dealing with stress and overall satisfaction are negatively associated. It might also imply that nurses have developed coping strategies to deal with stressful situations. Job related stress is becoming increasingly big syndrome among nurses [7] Stress has a cost for the individual in terms of health and well-being and for the organization in terms of absenteeism and turnover which is indirectly affecting quality of care provided to the patient [7].

This finding is important and should help focus appropriate organizational and professional change strategies. It is evident that the nurses in this study, despite their descriptions and experiences of stress, continue to work in their profession as they enjoy what they do. Managers could escalate all efforts to foster and further develop collegial and respectful relationships in full appreciation of the outcomes of this research. Nurses who are currently working in the system need to be appropriately praised and rewarded by senior management for their good work to enhance morale and camaraderie so that they feel they are being recognized and valued for the work they enjoy doing and for which they feel suited. This research identifies the very positive levels of enjoyment and satisfaction described by the nurses despite the acknowledged highly stressful work. Recognizing and balancing these seemingly conflicting factors needs to be considered when developing appropriate supportive human resource work place strategies.

However, high stressors may nonetheless continue to pose risks and these can be handled through the institution of formalized peer support and clinical guidance systems within the hospitals. With such an intervention, the nurses can have co-workers and professionals or leaders to talk to about difficult events or situations whose intensity could cause trauma or extreme stress and to which they have been exposed. It is further recommended that, workload issues should be tackled. The nurse's role and responsibilities should be clearly defined and his or her workload also be brought in line with his or her capabilities and resources. Work timetables should be made well-suited with demands and responsibilities outside the job in order to reduce the feeling of too much to do and too little time in which to do it.

There should be a well structured hospital work environment to provide the nurses with access to opportunity, information, resources, and power. This can endow the nurse psychologically by improving his or her autonomy, growing his or her confidence and power, and generally helping him or her in efforts at giving meaning to his or her work. This may result in job satisfaction, a greater sense of personal accomplishment and less occupational stress.

For further research, studies need to be conducted in KAMC on occupational stress. Whilst there is sufficient evidence in several other countries to believe that work stress is a factor among health care personnel. Researches are needed to augment the understanding of stress in KAMC and its effect on patient outcomes in particular. In order to derive a better understanding of job stress in nurses and healthcare workers in KAMC, research with a wider scope is needed. The present study has been conducted using only critical care areas and this is why a more comprehensive scope and methodology should be used to explore the topic further.

\section{ACKNOWLEDGEMENTS}

We are grateful to Institutional Review Board for giving us the ethical clearance to conduct the research. Without their permission, this study would not have been possible. Our most sincere thanks go to all the Nurses of Critical Care Areas who participated in the study.

\section{REFERENCES}

1. Hersch, R. K., Cook, R. F., Deitz, D. K., Kaplan, S., Hughes, D., Friesen, M. A., \& Vezina, M. (2016). Reducing nurses' stress: A randomized controlled trial of a web-based stress management program for nurses. Applied nursing research, 32, 18-25.

2. McHugh, M. D., Kutney-Lee, A., Cimiotti, J. P., Sloane, D. M., \& Aiken, L. H. (2011). Nurses' widespread job dissatisfaction, burnout, and frustration with health benefits signal problems for patient care. Health Affairs, 30(2), 202-210.

3. Abarghouei, M. R., Sorbi, M. H., Abarghouei, M., Bidaki, R., \& Yazdanpoor, S. (2016). A study of job stress and burnout and related factors in the hospital personnel of Iran. Electronic physician, 8(7), 2625.

4. Khamisa, N., Peltzer, K., \& Oldenburg, B. (2013). Burnout in relation to specific contributing factors and health outcomes among nurses: a systematic review. International journal of environmental research and public health, 10(6), 2214-2240.

5. Alonso, A., Baker, D. P., Holtzman, A., Day, R., King, H., Toomey, L., \& Salas, E. (2006). Reducing medical error in the military health system: how can team training help?. Human Resource Management Review, 16(3), 396-415.

6. Billeter-Koponen, S., \& Fredén, L. (2005). Longterm stress, burnout and patient-nurse relations: qualitative interview study about nurses' experiences. Scandinavian Journal of Caring Sciences, 19(1), 20-27.

7. Gulavani, A., \& Shinde, M. (2014). Occupational stress and job satisfaction among 
nurses. International Journal of Science and Research (IJSR), 3(4), 733-740.

8. Khamisa, N., Peltzer, K., \& Oldenburg, B. (2013). Burnout in relation to specific contributing factors and health outcomes among nurses: a systematic review. International journal of environmental research and public health, 10(6), 2214-2240.

9. Rothberg, M. B., Abraham, I., Lindenauer, P. K., \& Rose, D. N. (2005). Improving nurse-to-patient staffing ratios as a cost-effective safety intervention. Medical care, 785-791.

10. Healy, C. M., \& McKay, M. F. (2000). Nursing stress: the effects of coping strategies and job satisfaction in a sample of Australian nurses. Journal of advanced nursing, 31(3), 681688.
11. Tennant, C. (2001). Work-related stress and depressive disorders. Journal of psychosomatic research, 51(5), 697-704.

12. Yang, D. (2017). Stress and Burnout in Demanding Nursing Home Care: A literature review of the causes, prevention and coping strategies.

13. Utriainen, K., \& Kyngäs, H. (2009). Hospital nurses' job satisfaction: a literature review. Journal of nursing management, 17(8), 1002-1010.

14. Irvine, D. M., \& Evans, M. G. (1995). Job satisfaction and turnover among nurses: Integrating research findings across studies. Nursing Research, 44(4), 246-253

15. Newman, K., Maylor, U., \& Chansarkar, B. (2001). The nurse retention, quality of care and patient satisfaction chain. International Journal of Health Care Quality Assurance, 14(2), 57-68.

\section{Questionnaire to measure stress level among critical care areas nurses during hajj season 2017 in KAMC}

This questionnaire is anonymous and will not affect your personal or professional life. You will take only 10 minutes to fill it.

\section{Research Participant Number} Date of Interview

1. Age;

$$
\text { 20-25, } \bigcirc 26-30, \bigcirc 30-35, \bigcirc \text { above } 35
$$

2. Gender;

$$
\bigcirc \text { Male nurse } \bigcirc \text { Female nurse }
$$

3. Country of birth
a) Saudi Arabia
b) Philippines
c) India
d) Pakistan
e) Jordan
f) Other

4. Current area of working
a) ICU
b) $\mathrm{CCU}$
c) $\mathrm{CSICU}$
d) $\mathrm{NICU}$

5. Total years of professional nursing experience (since you have completed your training and become a registered nurse)
a) 1-4 years
b) 4-8 years
c) 8-12 years
d) > 12 years

6. Years' experience in KAMC during Hajj Season.
a) 1-years
b) 2-years
c) 3-years
d) More than 3years

7. How often you feel stressed at your working area?
Never
occasionally
$\bigcirc$ frequently
most often
always

8. How often you feel excessive workload? 

Never
Occasionally
$\bigcirc$ frequently
$\bigcirc$ most often
Always

9. Do you have to rush to complete your tasks?

Never $\bigcirc$ occasionally $\bigcirc$ frequently $\bigcirc$ most often $\bigcirc$ Always

10. Are you finishing late your assigned work?
O Never
occasionally
$\mathrm{O}$ frequently
○most often
always

11. Do you think you are achieving more than time allows?
O Never
Ooccasionally
$\bigcirc$ frequently
Omost often
always

12. Do you think your hospital expects more than reasonably possible?
Never
$\bigcirc$ occasionally
$\bigcirc$ frequently
most often
Always

13. Do you have a strong sense of commitment toward your work?
Never
Always
$\bigcirc$ occasionally $\bigcirc$ frequently $\bigcirc$ most often

14. Are you constantly looking for challenge?
ONever
occasionally
$\bigcirc$ frequently
Omost often
always

15. Do you think that you are being valued from your clients?
ONever
Occasionally
$\bigcirc$ frequently
most often
always

16. How often you feel that your colleagues are supportive?
Never
Ooccasionally
frequently
$\bigcirc$ most often
always

17. Do you feel that you have an organizational support?
O Never
occasionally
$\bigcirc$ frequently
most often
always

18. How often do you feel emotionally drained at work?

Never $\bigcirc$ occasionally $\bigcirc$ frequently $\bigcirc$ most often $\bigcirc$ always

19. How often are you apathetic toward your client?
O Never
Occasionally
$\bigcirc$ frequently
most often
Oalways

20. How often are you apathetic toward your colleagues?
O Never
occasionally
$\bigcirc$ frequently
most often
Always

21. How often you feel low morale?
Never
occasionally
$\bigcirc$ frequently $\bigcirc$ most often
Always

22. Do you think you are undervalued at your work?
O Never
$\bigcirc$ occasionally
$\mathrm{O}$ frequently
most often
always

23. Do you have feeling of incompetence?
ONever
$\bigcirc$ occasionally
$\bigcirc$ frequently
most often
Oalways

24. Are you afraid to express your needs?
O Never
$\bigcirc$ occasionally
$\bigcirc$ frequently
$\bigcirc$ most often
always

25 . Your working environment increases anxiety.
Never
occasionally
$\bigcirc$ frequently
most often
always

26. How often are you fatigued from your work?
O Never
Occasionally
frequently
most often
○lways

27. How often do you participate in any decision making related to your job?
ONever
$\mathrm{O}$ occasionally
$\bigcirc$ frequently
O most often
$\mathrm{O}$ always 
28. Do you really enjoying the type of your work?
Never
occasionally
$\bigcirc$ frequently
$\bigcirc$ most often
always

29. Do you want to change your area of practice?
Never
occasionally
frequently
most often
always

30. Do you think you have physical problem like headache and sleeplessness due to your work?
Never
occasionally
$\bigcirc$ frequently
$\bigcirc$ most often
always

31. Do you feel helplessness?
Never
$\bigcirc$ occasionally
$\bigcirc$ frequently
$\bigcirc$ most often
Always

32. How often you feel that you are being depressed by your working environment?
Never
occasionally
frequently
most often
always

33. Do you think your level of irritability is increasing because of your job?
Never
occasionally
frequently
most often
always

34. How often did you have sick leave for more than one day over last 6 months
Never
occasionally
$\bigcirc$ frequently
$\bigcirc$ most often
always

35. What are the techniques you are using to cope with your stress level?

(You can tick more than one)
A. Deep breathing
B. Drinking tea, coffee or any other beverage
C. Exercise/ yoga/ meditation
D. Musical therapy
E. Others.

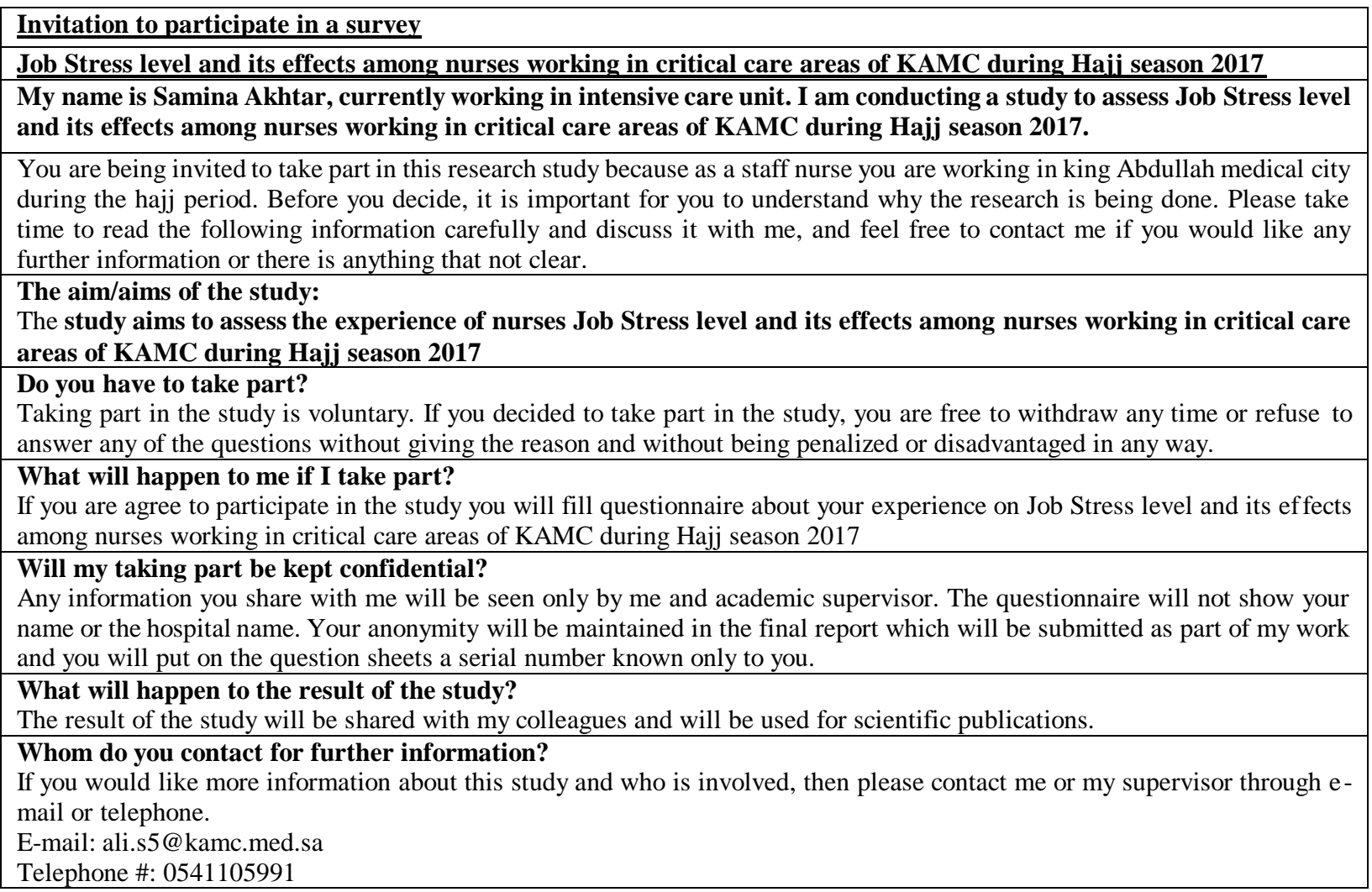

